
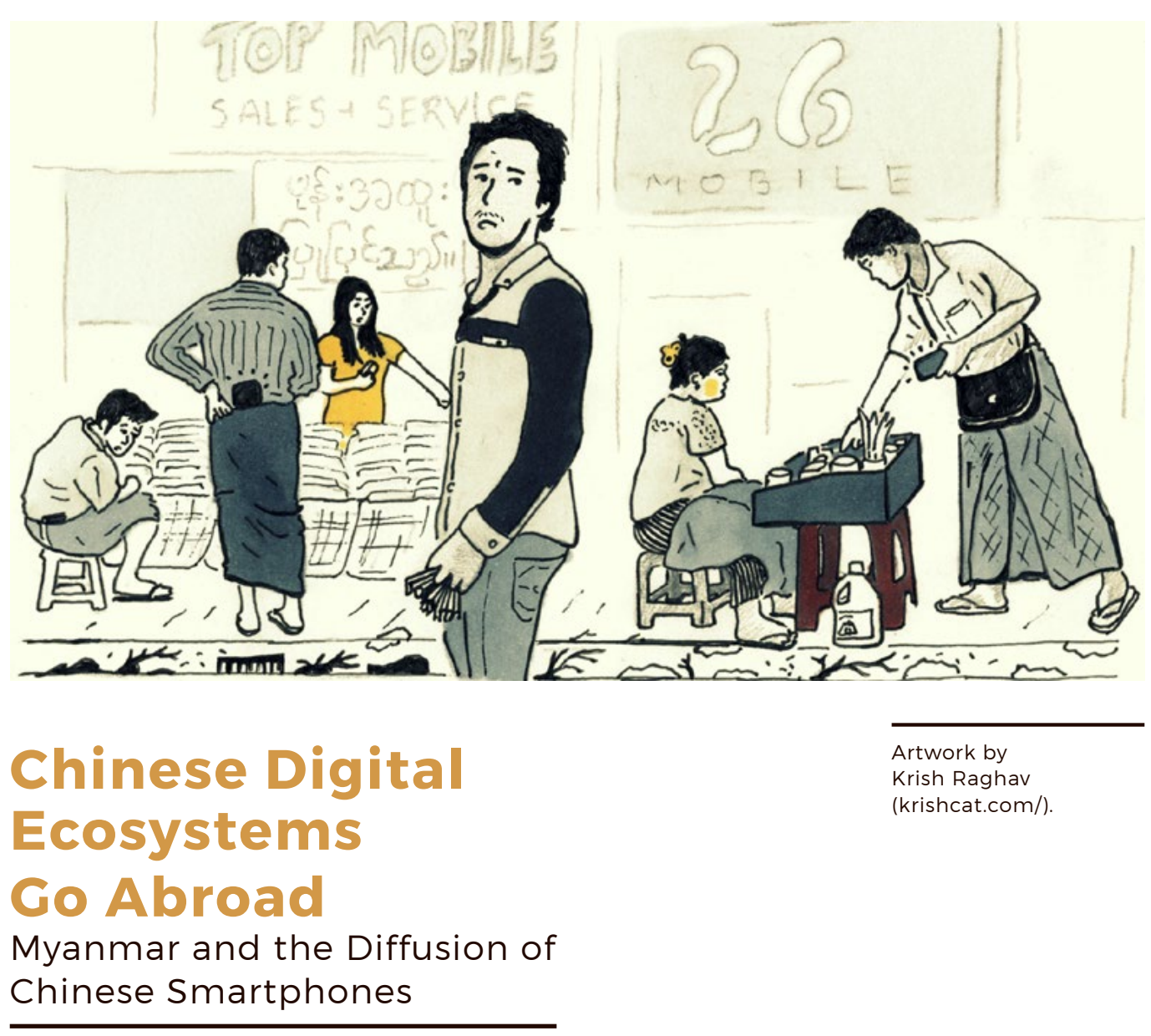

\title{
Elisa OREGLIA
}

Myanmar's recent economic opening has prompted a dramatic upsurge in access to mobile phone and Internet technologies. Lower-cost smartphones finding their way across the border from China often have limited Burmese language support and come with WeChat and other Chinese apps preinstalled. This situation is resulting in a localised form of China's digital ecosystem with Burmese characteristics.
Artwork by Krish Raghav (krishcat.com/). 
new, enthusiastic adopters among Shan state traders, who have figured out creative ways of adjusting functions aimed at the Chinese market for their own purposes. Take WePay for example-one of the most popular features on WeChat, this built-in payment feature that makes purchasing and transferring money in China so convenient is not available in kyat, the Myanmar currency. And yet there are Burmese traders, shopkeepers, and buyers who regularly use it to conduct business both within Myanmar and across the border with China, ending up with Chinese renminbi stored in their WeChat account that theoretically cannot be cashed out and converted into kyat. They have devised clever workarounds to do so: they can cash the renminbi out through informal agents that are based in Myanmar but have business (or family) contacts in China, for a small fee; or they can buy the equivalent value in products in China that they will then import back to Myanmar. The money never materialises: it becomes a creative encounter of digital payments, barter exchanges, and cross-border trade.

\section{Breaking the Isolation}

These are very recent developments in Myanmar, a country that has been going through decades of turmoil and international isolation. Until 2014 or 2015, retail commerce was a slow and cumbersome affair. Many small town and rural business people did not have a phone-be it a landline or a mobile-and had to rely on visits from travelling agents, or go themselves to wholesale markets, typically by bus on dangerous roads or by train on slow railway lines. Myanmar had been rather secluded from the outside world during the years of the military dictatorship (1964-2011), which had not only censored media and communications, but also neglected basic infrastructure, making it exceedingly difficult and expensive for people to get and use landlines, computers, and mobile phones, among other things. Telecommunications were a state monopoly, run by Myanmar Posts and Telecommunications. In 2010, there were only 594,000 mobile phone subscribers in the country, equal to 1.14 subscriptions per 100 inhabitants, and 493,314 landline subscribers, or 0.98 per 100 inhabitants (ITU 2017a and 2017b). The cost of SIM cards was out of reach for most people, hovering around 2,000 USD in the late 2000s, and still in the hundreds of dollars in the early 2010s. Private landlines were exceedingly rare, especially outside major cities, so people used public phones, which were also expensive and unreliable. Communication for either personal or business purposes was not easy.

The situation started to change in 2011, with the economic liberalisation programme carried out by the new government. Censorship of media was dropped and the telecommunication market was opened to foreign operatorswith Norwegian company Telenor and Qatari company Ooredoo winning the licence to build and operate new mobile networks. Both companies started service in August 2014, with results that went well beyond the most optimistic expectations. The price of SIM cards dropped almost overnight to 1.5 USD, and people started to acquire both SIM cards and mobile phones at a swift pace. The number of mobile subscription went from $6,832,380$ in 2013 (12.83 per 100 inhabitants) to $29,029,342$ (54.05 per 100 inhabitants) in 2014 (ITU, 2017b), and reached an impressive 89.8 mobile subscriptions per 100 inhabitants in 2017 (ITU 2018), while fixed telephone subscriptions still languished at about 514,385 (ITU 2017a). The country has gone mobile, not only in terms of phones, but also in terms of Internet access, with 75.1 mobile broadband subscriptions per 100 inhabitants in 2017 (ITU 2018).

As a consequence, the number of mobile phone shops has grown as exponentially as the number of users of mobile phones. But while cities and bigger towns feature shops that would not be out of place in any urban area in wealthier countries, more rural and isolated places have to make do with small shops that offer a very limited choice. An urban shop will 
provide the whole gamut of phones, from the latest Samsung and Apple smartphones, costing around 1,000 USD, to entry-level feature phones at 15 USD and everything in between. These phones are all imported legally, sold with full warranty, and might offer native support for Burmese language-or at least come with a Burmese font keyboard installed-not a given in a country that has long been plagued by the existence of two incompatible ways of inputting and rendering Burmese: Zawgyi and Unicode. A rural shop, on the other hand, will sell mostly Chinese brands that occupy the mid- and lowend of the market. The prices for smartphones range from 35 USD at the lowest end, to 180 USD at the upper end. Some are budget models of well-known brands such as Huawei, its subsidiary Honor, and Oppo. Others are 'local' brands, whose phones are made in China, and whose commercial distribution, marketing, and sales are managed by Chinese entrepreneursfor example a brand called Kenbo, which (potentially by design) shares its name with a very popular brand of motorcycles. Others still are Chinese brands like Coolpad, Gionee, Vivo, Meizu, and Zopo, typically unknown in the West, but that have been gaining significant market shares in emerging economies. While these phones are cheap, and can provide smartphone capabilities and Internet access to people who would otherwise be excluded, there are trade-offs in terms of durability and usability.

\section{A New Internet Underclass?}

The overall experience of mobile phone users who buy the cheaper kind of smartphones begins not only with a much smaller choice in terms of brands and features, but also with salespeople who might not know exactly what they are selling-some general goods stores simply add a few phones to their inventory, and do not provide any kind of support nor adviceand with phones that might have been imported through informal channels. This was-and still is-particularly true in Shan state, where porous borders mean that there continues to be a significant amount of goods being smuggled in from China, including mobile phones, in order to avoid import duty (Wai 2014).

These phones are usually purchased in Chinese shops, and are not meant for the export market; while their operating system is the now ubiquitous Android, it is often the Android adapted to the Chinese market-that is, without the default suite of Google apps that come preinstalled, which are instead substituted by Chinese apps. These phones are adapted to the Myanmar market before being sold, but they maintain traces of the Chinese Internet ecosystem: the operating system is a mix of English and Chinese, rather than Burmese, even after the default language is switched to English (at the time of my research, there was no operating system in Burmese at all). This creates a set of challenges even for people who are literate-but in their own native language rather than in English or Chinese. They range from difficulties in navigating the phone interface and understanding 'housekeeping' messages, such as notices of available updates, warnings regarding memory or performance, etc., to serious obstacles in using text-based interfaces, such as SMS or search. The journey to mobile Internet use, thus, often starts in an environment that is unfamiliar, as most people did not have any experience with digital devices before getting their smartphone, and in a language (or two) not well known, or completely unknown. Even as these challenges are negotiated and workarounds are developed, there are still barriers related to access, since connectivity is still patchy outside urban areas, the network can be very slow at peak usage times, and data cost can be significant, especially for people with limited budgets.

While affordable smartphones and the fast build-up of infrastructure have allowed millions of people to go online, mobile-only Internet access is not the panacea that it was expected to be in the early days of the debate on the so- 
called digital divide. More people have access to the Internet, but their Internet looks quite different from the one that users in wealthy, urban areas across the world take for granted. The 'Emerging Mobile Internet Underclass,' as Napoli and Obar (2014) called it, is using an Internet with lower levels of functionality, less content, more closed platforms, and more difficulties in creating content and looking for information than people using computers. While not all these issues were equally relevant in Myanmar, the point remains that smartphone use, and Internet use through smartphones, present serious challenges to new users, and the combination of default settings and intermediaries make a significant difference in how people are able to leverage their devices. What is preinstalled on the phone is key, as many people that face the budget and technical challenges I mentioned above will not install new apps, or if they do they will do so through intermediaries, e.g. the many shops that offer 'download and maintenance' support, for a fee.

\section{A WeChat for All Seasons}

Smartphones coming from China often have WeChat preinstalled, and Shan state already has a significant WeChat user base due to the commercial ties with China, meaning that the app is quite widespread for both business and personal use. Its features are also a particularly good match for mobile Internet users with low levels of literacy and on bad networks: much can be done by using a combination of photos, voice messages, videos, emoticons, and even the built-in Chinese to English translation capability. A market vendor I interviewed said that she took photos of the goods she needed to reorder, and sent them to her existing suppliers, who then shipped the packages via bus. The added bonus for her was that she could compose her 'order' regardless of the state of the network, which at the time was so overloaded as to be often unusable during the day, knowing everything would be sent later on, typically at night. She received a call from the bus station when her goods arrived, and went to collect them without having to wait for the agent to come and visit, or having to travel to the suppliers herself. In her case, the payment was done through the bus operator, that worked as a sort of payment clearing house for local businesses (Oreglia and Srinivasan 2016). Other bigger traders were doing international business using the same tactics. Relationships were established with suppliers (or buyers, in the case of agricultural products and natural resources) in person, which served to create the initial trust, but subsequently carried out via WeChat, including WePay payments.

Thus, WeChat, the quintessential symbol of the Chinese Internet, is being adopted and adapted in other countries. In general, the connection with China remains, as most of the use that I have witnessed has included some kind of trade link with the country. What is remarkable, however, is that this is happening outside the localisation strategy of Tencent-which launched WeChat in Burmese in 2015-and is mostly parallel to, rather than fully integrated with, the formal economy. The WeChat usage I have observed is either in Chinese or in English, but for the users it did not matter much: they rarely explored options outside the main instant messaging area, and their way of using the app bypassed written language almost entirely. The goods bought and sold on the app were sometimes bought legally, but often illicitly smuggled in or out of Myanmar, and currencies travelled equally fluidly across borders. As both the app and Chinese smartphones find a large user base in the Global South, it will be interesting to see whether the Chinese Internet becomes a sort of 'second Internet', as former Google CEO Eric Schmidt put it (Kolodny 2018), quite independent from the one led by the United States, or whether a new hybrid will emerge, that will mix Chinese and US technology with local business and social practices. 
This text is taken from Dog Days: A Year of Chinese Labour, Civil Society, and Rights, Made in China Yearbook 2018, edited by Ivan Franceschini and Nicholas Loubere, published 2019 by ANU Press, The Australian National University, Canberra, Australia.

doi.org/10.22459/MIC.04.2019.42 